\title{
The angiotensin II receptor antagonist candesartan cilexetil (TCV-116) ameliorates retinal disorders in rats
}

\author{
Y.Nagisa $^{1}$, A. Shintani ${ }^{1}$, S. Nakagawa ${ }^{2}$ \\ ${ }^{1}$ Pharmacology Research Laboratories II, Pharmaceutical Research Division, Takeda Chemical Industries, Osaka, Japan \\ ${ }^{2}$ Scientific Information, Pharmaceutical Business Development Department, Takeda Chemical Industries, Osaka, Japan
}

\section{Abstract}

Aims/hypothesis. The results of the EUCLID trial (EURODIAB Controlled Trial of Lisinopril in Insulin-dependent Diabetes Mellitus) highlighted the importance of the renin-angiotensin system in the pathogenesis of diabetic retinopathy. Candesartan cilexetil (TCV-116), a potent angiotensin II (AII) receptor antagonist, has beneficial effects on hypertension as well as on heart, renal and cerebrovascular disease. We aimed to evaluate the effectiveness of candesarten cilexetil in ameliorating retinal disorders induced by hyperglycaemia.

Methods. We compared retinal vascular endothelial growth factor (VEGF) mRNA expression and the latencies of retinal oscillatory potentials in TCV-116treated and control groups of stroke-prone spontaneously hypertensive rats with streptozocin (STZ)-induced diabetes.

Results. Retinal VEGF mRNA expression was significantly higher and the latencies of oscillatory potentials were significantly elongated in STZtreated spontaneously hypertensive rats compared with a non-treated spontaneously hypertensive rat group matched for age. These changes were dependent on hyperglycaemia but independent of hypertension. Treatment with TCV-116 (3 mg/kg) significantly diminished retinal VEGF mRNA expression and the latencies of oscillatory potential peaks, but had no effect on plasma glucose concentrations.

Conclusion/interpretation. These results suggest that TCV-116 is effective in preventing the development of diabetic retinopathy already in the early stages. [Diabetologia (2001) 44: 883-888]

Keywords Candesartan cilexetil (TCV-116), retina, vascular endothelial growth factor, oscillatory potentials, streptozocin, stroke-prone spontaneously hypertensive rats.
Diabetic retinopathy, one of the most serious complications of diabetes, is caused by a microvascular disorder. The risk of retinopathy is directly related to the degree and duration of hyperglycaemia [1]. Ac-

Received: 23 December 2000 and in revised form: 2 March 2001

Corresponding author: Y. Nagisa, 2-17-85 Juso-honmachi, Yodogawa-ku, Osaka, 532-8686, Japan, e-mail: Nagisa_Yasutaka@takeda.co.jp

Abbreviations: EUCLID, EURODIAB Controlled Trial of Lisinopril in Insulin-dependent Diabetes Mellitus; RAS, renin-angiotensin system; AII, angiotensin II; VEGF, vascular endothelial growth factor; SHRSP, stroke-prone spontaneously hypertensive rat; STZ, streptozocin; ERG, electroretinogram. cording to a report $80 \%$ of Type I (insulin-dependent) diabetic patients develop retinopathy within 15 years of diagnosis [2]. Diabetic retinopathy occurs in three pathological stages [3]. The earliest phase is background retinopathy involving increased retinal vasopermeability, retinal vascular microaneurysms and bolt haemorrhages and cotton wool spots. The second stage is pre-proliferative retinopathy with vascular occlusion. Finally, the advanced stage is proliferative retinopathy with fibrovascular proliferation and neovascularization. Occasionally, retinal detachment occurs at this stage. A major problem with diabetic retinopathy is the lack of subjective symptoms so that, by the time patients become conscious of an abnormality in their vision, it is too late to cure the condition. Diabetic retinopathy is therefore the pri- 
mary cause of adult-onset blindness, which has serious consequences for patients' quality of life. The main forms of treatment currently available for diabetic retinopathy are laser photocoagulation for neovascularization and vitrectomy for membrane proliferation and retinal detachment. However, in several cases, these surgical treatments have not been suitable or vision has not been restored even though surgery was apparently successful. Therefore, an anti-retinopathy agent which can be used from the early stages of diabetic retinopathy is desirable.

The results of the EUCLID study have highlighted the importance of the renin-angiotensin system (RAS) in the pathogenesis of diabetic retinopathy [4]. Several clinical and in vitro studies have also suggested a close relation between the RAS and diabetic retinopathy [5-9]. Candesartan cilexetil (TCV-116) is a potent AT1 angiotensin II (AII) receptor antagonist which has beneficial effects on hypertension and on heart, renal and cerebrovascular disease [9-12]. To evaluate its effectiveness in treating diabetic retinopathy, we studied changes in retinal vascular endothelial growth factor (VEGF) mRNA expression and the latencies of retinal oscillatory potentials in a new rodent model of diabetic retinopathy, strokeprone spontaneously hypertensive rats (SHRSP) with streptozocin (STZ)-induced diabetes. The VEGF is thought to be a major pathological factor in the promotion of diabetic retinopathy because of its potent effects on endothelial cell growth and vasopermeability [13]. Furthermore, vitreal VEGF concentrations are higher in patients with diabetic retinopathy and the expression of retinal VEGF mRNA is increased in animal models of this condition [14-20]. In addition, prolongation of the latencies of retinal oscillatory potential peaks is known to be a physiological change that occurs in the very early stages of diabetic retinopathy [21].

\section{Materials and methods}

Animals and drugs. All animal experiments were carried out according to the guidelines of the Takeda Experimental Animal Care and Use Committee. A total of 24 male 11-week-old SHRSP (SHRSP/Ta: Takeda Chemical Industries, Osaka, Japan) were injected intravenously with STZ at a dose of $30 \mathrm{mg} /$ $\mathrm{kg}$. Nine weeks after the administration of STZ, their body weights, blood pressures and plasma glucose concentrations were measured. They were then divided into a control group $(n=6)$, a TCV-116 $1 \mathrm{mg} / \mathrm{kg} /$ day-treated group $(n=6)$ and a TCV-116 $3 \mathrm{mg} / \mathrm{kg} /$ day-treated group $(n=6)$. The appropriate doses of TCV-116 were suspended in $0.5 \%(\mathrm{w} / \mathrm{v})$ methylcellulose solution. Either TCV-116 or vehicle $(0.5 \%$ methylcellulose solution) was given orally once a day for 28 days. Body weight was measured at 2-day or 3-day intervals. Blood pressure and heart rate were measured 14 and 28 days after treatment started, while plasma glucose concentrations were measured 13 and 28 days after treatment started. An electroretinogram (ERG) was done 28 days after starting treatment. After the ERG, the rats were killed by exsanguination under deep anaesthesia with ether. Their eyes were enucleated, frozen immediately and stored at $-80^{\circ} \mathrm{C}$. A non-treated group was also included in the study. This consisted of 5 male 24-week-old SHRSP rats which underwent the ERG and had their eyes enucleated as described above. One rat in the TCV-116 (3 mg/ $\mathrm{kg}$ )-treated group had an extremely low body weight and was excluded from the experiment because of the marked difference in its physiological condition compared with the other rats. Accordingly, the number of non-treated rats was 5 .

Plasma glucose concentration. Blood for the plasma glucose measurements was obtained by an incision in a tail vein and collected into heparinized tubes. Plasma glucose concentration was measured using an autoanalyzing system (7070; Hitachi Corporation, Tokyo, Japan).

Cardiovascular parameters. Blood pressure and heart rate were measured by a tail-cuff method (BP-98A; Softlon, Tokyo, Japan). When the rats were still conscious, the tail arterial pressure was measured 6-10 times and the mean value was calculated.

ERG measurements. ERGs were done following Sato's methods [22]. In brief, after being kept in a dark room for 90-120 min, the rats were anaesthetized with ketamine hydrochloride (50 mg/kg, i.m., Ketaral, Sankyo, Tokyo, Japan) and xyladine ( $2 \mathrm{mg} / \mathrm{kg}$, i.m., Selactar, Bayer, Osaka, Japan) and their heads and legs were tied to the measuring table. The left pupil was maximally dilated with tropicamide (Midorin-P, Santen, Osaka, Japan) and a contact lens-type bipolar electrode (Kyoto Contact Lens Laboratory, Kyoto, Japan) was placed on the cornea. A xenon lamp (1.2 joule) was placed $10 \mathrm{~cm}$ above the left eye and controlled using a lighting stimulator (SLS3100, Nihon Kohden, Tokyo, Japan). The ERG impulses evoked by light stimuli ( $0.5 \mathrm{~Hz}$, applied 32 or 48 times $)$ were amplified and recorded using a Neuropack (MEB-5100, Nihon Kohden, Tokyo, Japan, low cut $0.5 \mathrm{~Hz}$, sweep time $200 \mathrm{~ms}$ ). The latencies of the oscillatory potential peaks $(\mathrm{O} 1, \mathrm{O} 2$ and O3) were determined from the ERGs using a digital caliper.

The VEGF mRNA assay. The RNA was isolated from the enucleated eyes with ISOGEN (Nippon-gene, Tokyo, Japan), chloroform, isopropanol and ether. The VEGF and $\beta$-actin mRNA levels were determined by a semi-quantitative reverse transcriptase-polymerase chain reaction (RT-PCR) analysis using a fluorescent-labeled TaqMan probe (ABI PRISM 7700, PE Biosystems Japan, Tokyo, Japan). In brief, the isolated RNA was added to a reaction mixture containing dUTP, dCTP, dATP, dTTP, rTth polymerase, forward and reverse primers for $V E G F$ and $\beta$-actin, and the fluorescent TaqMan probes for $V E G F$ (FAM) and $\beta$-actin (VIC). The RT-PCR was then done under the following conditions: $50^{\circ} \mathrm{C}$ for $20 \mathrm{~min}, 60^{\circ} \mathrm{C}$ for $30 \mathrm{~min}, 95^{\circ} \mathrm{C}$ for $5 \mathrm{~min},\left(94^{\circ} \mathrm{C}\right.$ for $20 \mathrm{~s}$ and $62^{\circ} \mathrm{C}$ for $\left.1 \mathrm{~min}\right) \cdot 40$ cycles. The sequences of the forward and reverse primers for $V E G F$ and $\beta$-actin, and of the fluorescent TaqMan probes for $V E G F$ (FAM) and $\beta$-actin (VIC), were as follows:

Rat $V E G F$ forward primer: CGTCGGAGAGCAACGTCACTAT

Rat $V E G F$ reverse primer: CTCATCTCTCCTATGTGCTGGCT

Rat $V E G F$ TaqMan probe: CAGATCATGCGGATCAAACCTCACCA

Rat $\beta$-actin forward primer: CCGTGAAAAGATGACCCAGATC

Rat $\beta$-actin reverse primer: CACAGAATGGATGGCTACGTA 


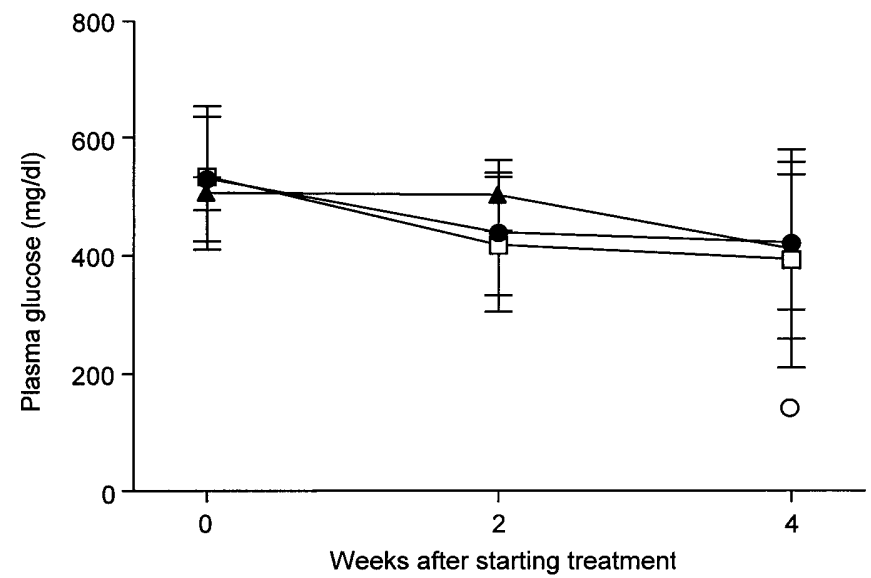

Fig. 1. Effect of TCV-116 on plasma glucose concentration in diabetic SHRSP rats. Nine weeks after injection of STZ $(30 \mathrm{mg} / \mathrm{kg})$, SHRSP rats were started on treatment with TCV-

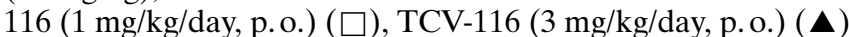
or vehicle $(0.5 \%$ methylcellulose in saline $)(0)$. Non-treated group $(\bigcirc)$ consisted of 24-week-old SHRSP rats. Each value represents means \pm S.D

Rat $\beta$-actin TaqMan probe: TTTGAGACCTTCAACACCCCAGCCA

The VEGF mRNA level was normalized by comparison with the $\beta$-actin mRNA level. Standard RNA was obtained from the retinas of Sprague Dawley rats (Japan Clea, Tokyo, Japan).

Statistical analysis. Values were expressed as the means \pm SD. Time-dependent changes in body weight, plasma glucose concentrations, heart rate and mean blood pressure were compared between the control group and the TCV-116-treated groups using analysis of variance. Statistical analyses of plasma glucose concentrations, retinal VEGF mRNA expression and the latencies of the oscillatory potentials 28 days after starting drug administration were done using a Dunnett-Type test. Statistical analyses of plasma glucose concentrations, retinal VEGF mRNA expression and the latencies of oscillatory potentials 28 days after starting vehicle administration in the control group and in the non-treated group were done using a Student's $t$-test. A value of less than 0.05 was considered to be statistically significant.

\section{Results}

Changes in body weight and plasma glucose concentrations. There were no differences in body weight between the control and TCV-116-treated groups during the dosing period (data not shown). The control, TCV-116 (1 mg/kg)-treated and TCV-116 (3 mg/ $\mathrm{kg})$-treated rats were all hyperglycaemic (530.4 \pm $106.4,532.8 \pm 121.4$ and $504.5 \pm 27.5 \mathrm{mg} / \mathrm{dl}$, respectively) on day 0 . These high plasma glucose concentrations were maintained throughout the dosing period and there were no differences in plasma glucose concentrations between the groups (Fig. 1).

Changes in cardiovascular parameters. In the control group, hypertension was maintained throughout the
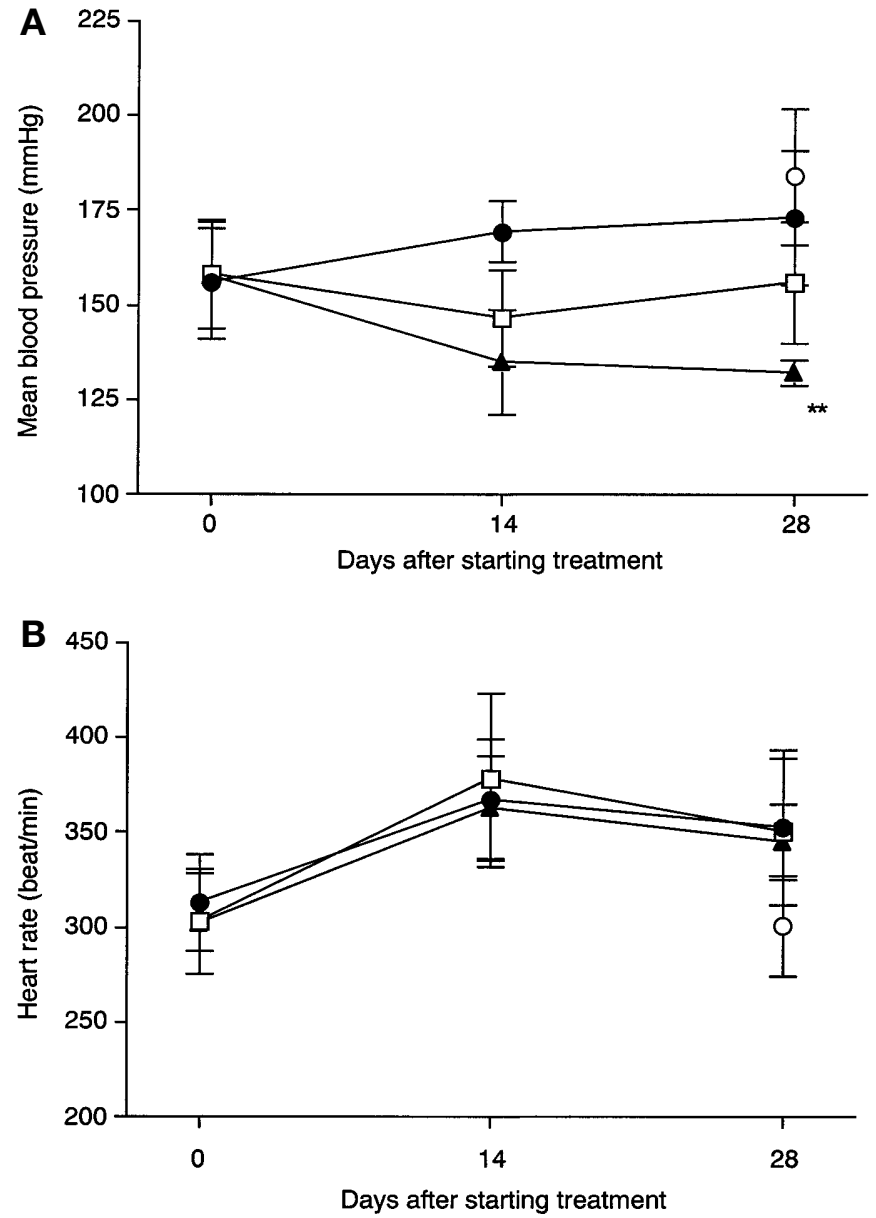

Fig. 2 (A, B). Effect of TCV-116 on mean blood pressure (A) and heart rate (B) in diabetic SHRSP rats. Nine weeks after injection of STZ $(30 \mathrm{mg} / \mathrm{kg})$, SHRSP rats were started on treatment with TCV-116 (1 mg/kg/day, p.o.) ( $\square)$, TCV-116 (3 mg/ $\mathrm{kg} /$ day, p.o.) ( $\boldsymbol{\Delta})$ or vehicle $(0.5 \%$ methylcellulose in saline $)$ (O). Non-treated group $(\bigcirc)$ consisted of 24-week-old SHRSP. Each value represents means \pm S.D. $* * p \leq 0.01$ vs Control group (Dunnett's test with ranked data at Day 28)

dosing period and the mean blood pressure on day $28(173 \pm 18 \mathrm{mmHg})$ was almost the same as that in the non-treated group $(184 \pm 18 \mathrm{mmHg})$. On the other hand, an analysis of variance showed that TCV-116 treatment had a dose-dependent hypotensive effect after day $14(\mathrm{~F}(2,14)=14.074, p<0.01)$, and the mean blood pressure in the TCV-116 $(3 \mathrm{mg} / \mathrm{kg})$ treatment group $(132 \pm 3 \mathrm{mmHg})$ was lower than in the control group $(p \leq 0.01)$. There were no differences in heart rate between the control and TCV-116 treatment groups (Fig. 2).

Changes in retinal VEGF $m R N A$ level. In the nontreated group, the retinal VEGF mRNA level was $1.077 \pm 0.047$ (the retinal VEGF mRNA level in the group of Sprague Dawley rats used for comparision was taken as 1). In the control group, the retinal VEGF mRNA level was $1.486 \pm 0.142$, a significant increase compared with the non-treated group 


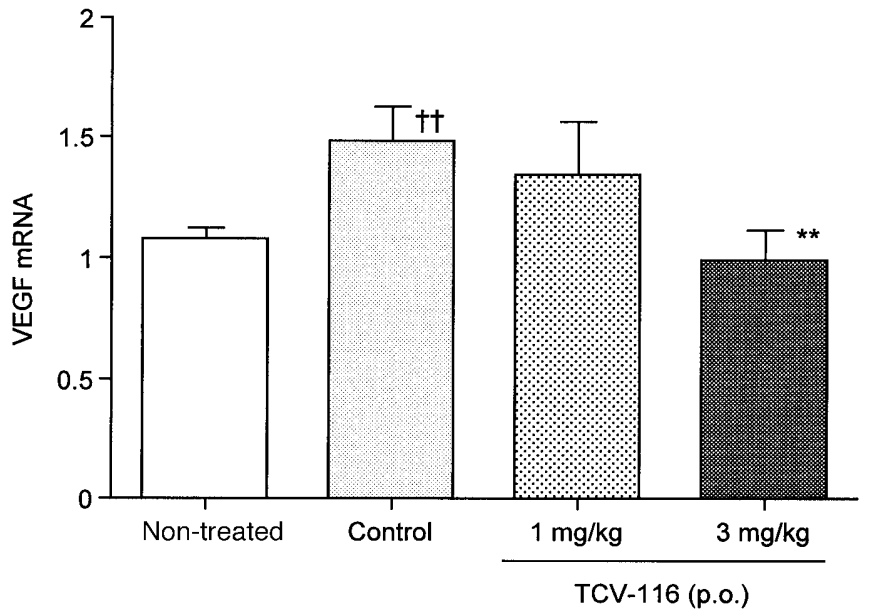

Fig.3. Effect of TCV-116 on retinal VEGF mRNA level in diabetic SHRSP rats. Nine weeks after injection of STZ $(30 \mathrm{mg} /$ $\mathrm{kg}$ ), SHRSP were started on treatment with TCV-116 or vehicle $(0.5 \%$ methylcellulose in saline $)$. The non-treated group consisted of 24-week-old SHRSP rats. Retinal VEGF mRNA level was normalised with beta-actin mRNA. Each value represents means $\pm \mathrm{S} . \mathrm{D} .{ }^{\dagger \dagger} p \leq 0.01$ vs non-treated group ( $t$-test), $* * p \leq 0.01$ vs control group (Dunnett's test)

Fig. 4 (A-D). Effect of TCV-116 on latency of oscillatory potentials (A-C) in diabetic SHRSP. Nine weeks after injection of STZ $(30 \mathrm{mg} / \mathrm{kg})$, SHRSP were started on treatment of TCV-116 or vehicle ( $0.5 \%$ methylcellulose in saline). Nontreated group consisted of 24-week old SHRSP rats. Each value represents means $\pm \mathrm{S}$. D. $\dagger p \leq 0.05$, $\dagger \dagger p \leq 0.01$ vs non-treated group ( $t$-test), * $p \leq 0.05$ vs control group (Dunnett's test with ranked data) $(p \leq 0.01)$. The retinal VEGF mRNA level in the TCV-116 $(1 \mathrm{mg} / \mathrm{kg})$-treated rats did not differ from that in the control group but the level in the TCV$116(3 \mathrm{mg} / \mathrm{kg})$-treated rats $(0.994 \pm 0.122)$ was lower $(p \leq 0.01)$, and similar to the normal level (Fig. 3)

Changes in ERGs. The latencies of the oscillatory potential peaks (O1, O2and O3) were elongated in the control group compared with the non-treated group $(\mathrm{O} 1: p \leq 0.01, \mathrm{O} 2: p \leq 0.01, \mathrm{O} 1: p=0.028)$. Treatment with TCV-116 $(1 \mathrm{mg} / \mathrm{kg})$ produced no changes in the latencies of the retinal oscillatory potentials compared with the control group but treatment with TCV-116 (3 mg/ $/ \mathrm{kg})$ diminished the latencies of $\mathrm{O} 1$, $\mathrm{O} 2$ and $\mathrm{O} 3$ (O1: $p=0.021, \mathrm{O} 2: p=0.029, \mathrm{O} 2$ : $p=0.012)$ (Fig.4).

\section{Discussion}

Several animal models of diabetic retinopathy have been described to date. Examples of experimental models of proliferative retinopathy include the prematurity retinopathy model in rats and mice and the laser coagulation-induced choroidal neovascularization model in rats and monkeys [17-19,23-24]. Hyperglycaemia-induced retinopathy models comprise STZ-induced diabetic rats and OLETF rats [25-27]. However, these experimental models are not considered to be suitable for the evaluation of antiretinopathy agents because of the low incidence of the condi-
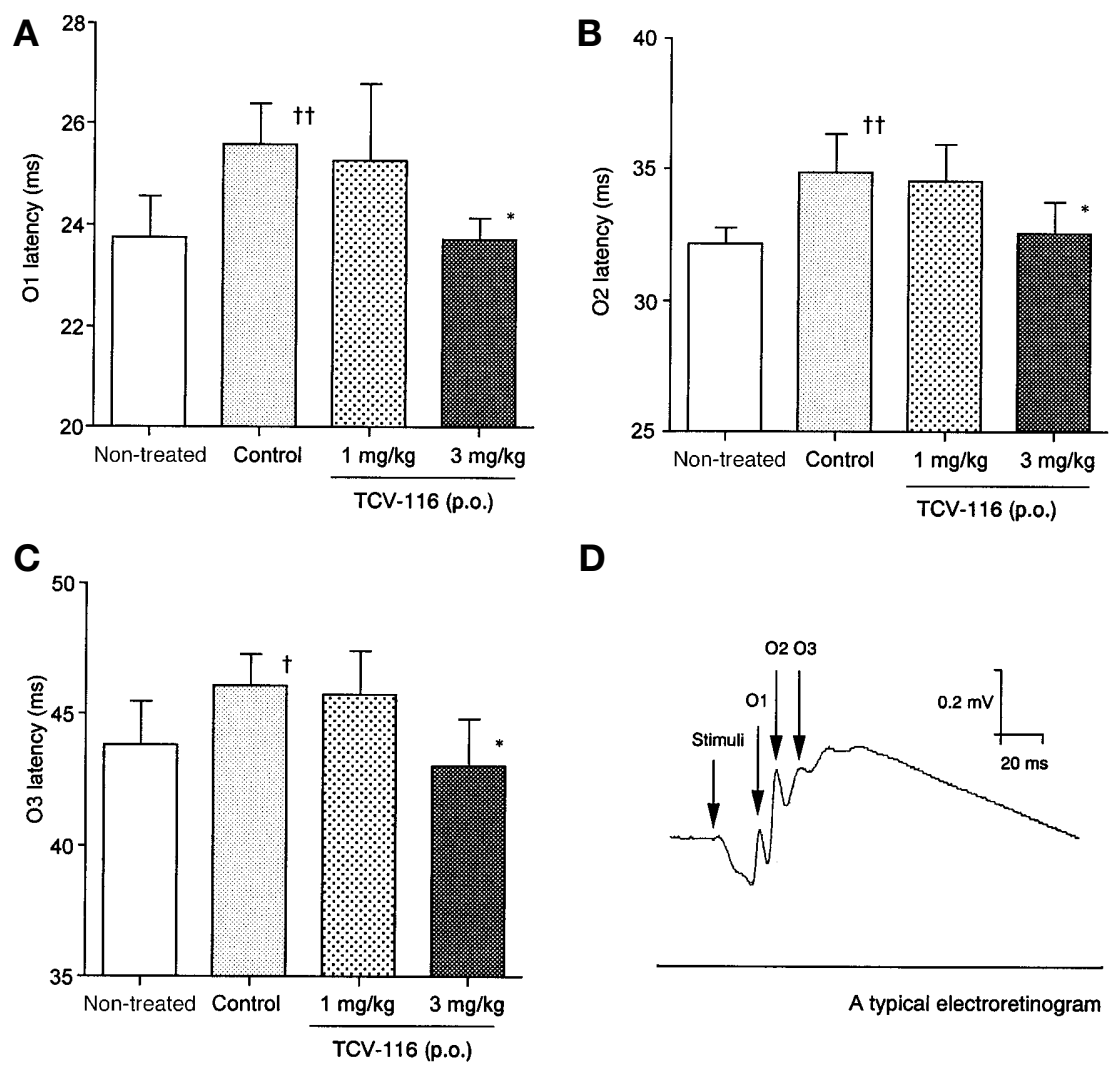

D

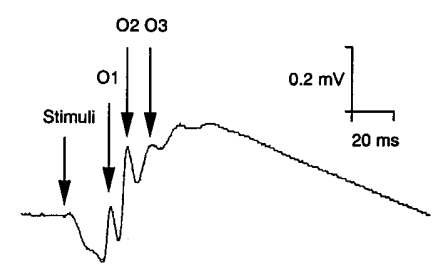

A typical electroretinogram 
tion and the long time for retinopathy to appear. For a high incidence rate and a short period for the development of retinopathy, the candidate animal model should possess vulnerable retinal vessels. For this reason, we chose stroke-prone spontaneously hypertensive rats (SHRSP), almost all of which develop strokes as well as malignant hypertension [29]. Because of the structural similarity between their retinal and cerebral vessels, SHRSP are expected to be equally as vulnerable to retinopathy as to strokes. Indeed, SHRSP have been reported to develop hypertension-induced retinal arterial strictures and retinal edema and electron microscopy studies have revealed abnormalities in their retinal vessels $[30,31]$. We evaluated the development of diabetic retinopathy in hyperglycaemic SHRSP induced by STZ injection using two indicators, retinal VEGF mRNA expression and changes in the latencies of oscillatory potentials. Both of these pathological changes are specific to diabetic retinopathy. In SHRSP with STZ-induced hyperglycaemia established over 3 months significant increases in retinal VEGF mRNA expression and elongation of the latencies of oscillatory potentials were observed. Although hypertension might cause the deterioration of the tissues and impair the retinal functions of SHRSP, the mean blood pressure of STZ-treated SHRSP was as high as that of age-matched non-treated SHRSP rats. This suggests that the increases in retinal VEGF mRNA levels and the elongation of the oscillatory potential latencies were dependent on hyperglycaemia. In Wistar rats with STZ-induced diabetes [27], a model of Type I diabetes, retinal VEGF mRNA expression has been reported to be higher 6 months after the STZ injection [27]. However, in OLETF rats, a model of Type II diabetes, increases in retinal VEGF mRNA expression and elongation of oscillatory potential latencies were observed at the age of 60 weeks [28]. In contrast, the SHRSP rats with STZ-induced diabetes described here showed typical pathological changes of diabetic retinopathy within a much shorter period of time (3 months). This model would therefore seem to be ideal for the evaluation of antiretinopathy agents and could also be used to study background and preproliferative retinopathy. This is because we did not find proliferative changes (which occur later in the natural history of diabetic retinopathy) in ocular fundus (data not shown), but did detect easily typical early changes, namely prolongation of the latencies of oscillatory potential peaks and increases in VEGF mRNA expression (which causes retinal edema), as in the Wistar rat model with STZ-induced diabetes and the OLETF rat model $[27,28]$.

Because RAS is thought to play an important role in the pathogenesis of diabetic retinopathy, we investigated the effectiveness of TCV-116, an AII receptor antagonist, in treating retinal disorders in SHRSP with STZ-induced diabetes [4]. TCV-116 reversed the increases in retinal VEGF mRNA levels and the pro- longation of oscillatory potential peak latencies that occur in this model but it had no hypoglycaemic effect.

The ameliorating effects of TCV-116 on retinal disorders could be caused by its hypotensive action because of the significant reduction of mean blood pressure in the TCV-116-treated groups. It is not likely, however, that hypertension would up-regulate the retinal VEGF mRNA level in non-treated SHRSP. This also explains why there is no difference in retinal VEGF mRNA levels between normotensive normoglycaemic Sprague-Dawley rats and hypertensive normoglycaemic SHRSP, suggesting that VEGF mRNA expression is not up-regulated by hypertension in the non-treated SHRSP rats. The comparison between the control and non-treated groups indicated that this reduction in blood pressure did not affect either retinal VEGF mRNA levels or the latencies of the oscillatory potential peaks in this model. The ameliorative effect of TCV-116 on diabetic retinopathy thus appears to be due to its direct antagonistic effect on AT1 receptors in the retinal tissue and to be independent of its hypotensive effect.

Recently, several reports on the relation between AII and diabetic retinopathy have been published. In a clinical study, serum angiotensin-converting enzyme activity was found to be higher in diabetic patients with retinopathy than in non-diabetic patients and the activity of this enzyme was found to be much higher in patients with proliferative retinopathy than in those with non-proliferative retinopathy [5]. In an in vitro study, AII promoted a marked increase in VEGF mRNA expression in vascular smooth muscle cells under high-glucose conditions and in retinal vascular pericytes $[6,7]$. The AII also induced the mRNA expression of KDR, one of the VEGF receptors, in retinal microvascular endothelial cells through the AT1 receptor [8]. Increased retinal VEGF mRNA expression could be especially important, as VEGF is thought to be a major factor leading to increased vasopermeability and neovascularization in background retinopathy and proliferative retinopathy. A local RAS, which is independent of the systemic RAS, has also been found in the eye [32]. Taken together, these results suggest that AII is an important cause of diabetic retinopathy. The ameliorative effects of TCV-116, an AT1 receptor antagonist, on diabetic retinopathy observed in our study support the idea of a relation between AII, VEGF and the pathogenesis of diabetic retinopathy.

In conclusion, our results suggest that TCV-116 is effective in preventing the development of diabetic retinopathy from the earliest stages of the condition.

Acknowledgements. We are grateful to Dr. H. Ikeda, Dr. T. Naka, Dr. Y. Sugiyama, Dr. Y. Inada and Dr. H. Odaka for critical discussions. We would like to thank Dr. R. Imai and Dr. M. Imawaka for technical advice on ERGs. 


\section{References}

1. Klein R, Klein BE, Moss SE (1989) The Wisconsin epidemiologic study of diabetic retinopathy: a review. Diabetes Metab Rev 5: 559-570

2. Klein R, Klein BE, Moss SE (1984) Visual impairment in diabetes. Ophthalmology 91: 1-9

3. Aiello LP, Gerdner TW, King GL et al. (1998) Diabetic retinopathy. Diabetes Care 21: 143-156

4. Chaturvedi N, Sjolie AK, Stephenson JM et al. (1998) Effect of lisinopril on progression of retinopathy in normotensive people with Type 1 diabetes. Lancet 351: 28-31

5. Van Dyk DJ, Erman A, Erman T, Chen-Gal B, Sulkes J, Boner G (1994) Increased serum angiotensin converting enzyme activity in Type I insulin-dependent diabetes mellitus - its relation to metabolic control and diabetic complications. Eur J Clin Invest 24: 463-467

6. Natarajan R, Bai W, Lanting L, Gonzales N, Nadler J (1997) Effect of high glucose on vascular endothelial growth factor expression in vascular smooth muscle cells. Am J Physiol 42: H2224-H2231

7. Otani A, Takagi H, Oh H, Suzuma K, Matsumura M, Ikeda E, Honda Y (2000) Angiotensin II-stimulated vascular endothelial growth factor expression in bovine retinal pericytes. Invest Ophthalmol Vis Sci 41: 1192-1199

8. Otani A, Takagi H, Suzuma K, Honda Y (1998) Angiotensin II potentiates vascular endothelial growth factor-induced angiogenic activity in retinal microcapillary endothelial cells. Circ Res 82: 619-628

9. Shibouta Y, Inada Y, Ojima M et al. (1993) Pharmacological profile of a highly potent and long-acting angiotensin II receptor antagonist, 2-ethoxy-1-[[2'- (1H-tetrazol-5yl)biphenyl-4-yl]methyl]-1H-benzimidazole-7-carboxylic acid (CV-11974), and its prodrug, ( + /-)-1-(cyclohexyloxycarbonyloxy)-ethyl-2-ethoxy-1- [[2'-(1H-tetrazol-5-yl)biphenyl-4-yl]methyl]-1H-benzimidazole-7-carboxylate (TCV-116). J. Pharmacol Exp Ther 266: 114-120

10. Kawamura M, Terashita Z, Okuda H et al. (1993) TCV116, a novel angiotensin II receptor antagonist, prevents intimal thickening and impairment of vascular function after carotid injury in rats. J Pharmacol Exp Ther 266: 1664-1669

11. Noda M, Matsuo T, Fukuda R et al. (1999) Effect of candesartan cilexetil (TCV-116) in rats with chronic renal failure. Kidney Int 56: 898-909

12. Inada Y, Wada T, Ojima et al. (1997) Protective effects of candesartan cilexetil (TCV-116) against stroke, kidney dysfunction and cardiac hypertrophy In stroke-prone spontaneously hypertensive rats. Clin Exp Hypertens 19: 1079-1799

13. Ferrara N, Houck K, Jakeman L, Leung DW (1992) Molecular and biological properties of the vascular endothelial growth factor family of proteins. Endocr Rev 13: 18-32

14. Adamis AP, Miller JW, Bernal MT et al. (1994) Elevated vascular permeability factor/vascular endothelial growth factor levels in the vitreous of eyes with proliferative diabetic retinopathy. Am J Ophthalmol 118: 445-450

15. Aiello LP, Avery RL, Arrigg PG. et al. (1994) Vascular endothelial growth factor in ocular fluid of patients with diabetic retinopathy and other retinal disorders. N Engl J Med 331: 1480-1487

16. Pe'er J, Folberg R, Itin A, Gnessin H, Hemo I, Keshet E (1996) Upregulated expression of vascular endothelial growth factor in proliferative diabetic retinopathy. $\mathrm{Br} \mathrm{J}$ Ophthalmol 80: 241-245
17. Pierce EA, Avery RL, Foley ED, Aiello LP, Smith LE (1995) Vascular endothelial growth factor/vascular permeability factor expression in a mouse model of retinal neovascularization. Proc Natl Acad Sci USA 92: 905-909

18. Stone J, Chan-Ling T, Pe'er J, Itin A, Gnessin H, Keshet E (1996) Roles of vascular endothelial growth factor and astrocyte degeneration in the genesis of retinopathy of prematurity. Invest Ophthalmol Vis Sci 37: 290-299

19. Ishibashi T, Hata Y, Yoshikawa H, Nakagawa K, Sueishi K, Inomata H (1997) Expression of vascular endothelial growth factor in experimental choroidal neovascularization. Lab Invest 235: 159-167

20. Robbins SG, Conaway JR, Ford BL, Roberto KA, Penn JS (1997) Detection of vascular endothelial growth factor (VEGF) protein in vascular and non-vascular cells of the normal and oxygen-injured rat retina. Growth Factors 14: 229-241

21. Shirao Y, Okumura T, Ohta T, Kawasaki K (1991) Clinical importance of electroretinographic oscillatory potentials in early detection and objective evaluation for diabetic retinopathy. Clin Vision Sci 6: 445-450

22. Sato S, Sugimoto S, Ando T, Miyajima H, Chiba S (1984) An electrophysiological method for detecting diabetic retinopathy in rats. Folia Pharmacol Jpn 84: 509-517

23. Aiello LP, Pierce EA, Foley ED et al. (1995) Suppression of retinal neovascularization in vivo by inhibiton of vascular endothelial growth factor (VEGF) using soluble VEGF-receptor chimeric proteins. Proc Natl Acad Sci USA 92: 10457-10461

24. Ishibashi T, Miller H, Orr G, Sorgente N, Ryan SJ (1987) Morphologic observations on experimental subretinal neovascularization in the monkey. Invest Ophthalmol Vis Sci 28: 1116-1130

25. Murata T, Ishibashi T, Khalil A, Hata Y, Yoshikawa H, Inomata H (1995) Vascular endothelial growth factor plays a role in hyperpermeability of diabetic retinal vessels. Ophthalmic Res 27: 48-52

26. Gilbert RE, Vranes D, Berka JL et al. (1998) Vascular endothelial growth factor and its receptors in control and diabetic rat eyes. Lab Invest 78: 1017-1027

27. Hammes HP, Lin R, Bretzel RG, Brownlee M, Breier G (1998) Upregulation of the vascular endothelial growth factor/vascular endothelial growth factor receptor system in experimental background diabetic retinopathy of the rat. Diabetes 47: 401-406

28. Segawa Y, Shirao Y, Yamagishi S et al. (1998) Upregulation of retinal vascular endothelial growth factor mRNAs in spontaneously diabetic rats without ophthalmoscopic retinopathy. Ophthalmic Res 30: 333-339

29. Okamoto K, Yamori Y, Nagaoka A (1974) Establishment of the stroke-prone spontaneously hypertensive rat (SHR). Circ Res 34-35 [Suppl 1]: 143-153

30. Hamada Y, Hamada M, Yonemoto H, Nakao Y, Otori T (1982) Fluorescent angiographic studies of hypertensive vascular changes of the retina of SHRSP. Nippon Ganka Gakkai Shi 86: 1301-1307

31. Lin WL, Essner E (1988) Ultrastructual and permeability characteristics of retinal vessels in stroke-prone spontaneously hypertensive rats. Graefes Arch Clin Exp Ophthalmol 226: 559-566

32. Wagner J, Jan Danser AH, Derkx FH et al. (1996) Demonstration of renin mRNA, angiotensinogen mRNA, and angiotensin converting enzyme mRNA expression In the human eye evidence for an intraocular renin-angiotensin system. Br J Ophthalmol 80: 159-163 